\title{
La democracia inestable. Cotejo de la obra de Tocqueville
}

\section{Unstable Democracy: Collating the Various Editions of Tocqueville's Book}

\author{
Eduardo Nolla ${ }^{1}$ \\ Universidad Francisco Marroquín (Guatemala)
}

Recibido: 12-04-19

Aprobado: 13-05-19

\section{Resumen}

Suponemos que un texto impreso goza de estabilidad. Sin embargo, esto no es así. En el caso de la Democracia en América, el paso del manuscrito a la impresión introdujo ya errores, y las sucesivas ediciones, otros nuevos. Algunas de estas erratas se han perpetuado en las ediciones más conocidas y traducidas. La identificación de estos errores ayuda a restituir el texto original y a comprender mejor la obra.

Palabras-clave: Tocqueville, Democracia en América, edición y traducción de textos clásicos.

\begin{abstract}
We suppose printed texts to be stable. This is not true. In Democracy in America's case, the move from manuscript to print already introduced some errors. Reprints of the book produced new ones. Some of these errors have persisted in the best known and most frequently translated, editions. Identifying the errors reconstructs the original text and helps to better understand the book.

Key-words: Tocqueville, Democracy in America, editing and translating of classical texts.

\footnotetext{
${ }^{1}$ (enolla@mac.com) editor y traductor de la primera edición crítica de La democracia en América de Tocqueville, publicada en Francia, España y los Estados Unidos. Ha escrito recientemente "Tocqueville's Pendulum: Thoughts on Religion, Liberty, and Reason in Democratic Times", en Michael Zuckert editor, The Spirit of Religion and the Spirit of Liberty. The Tocqueville Thesis Revisited y "Hidden from View: Tocqueville's Secrets", en Christine Henderson editor, Tocqueville's Voyages. The Evolution of his Ideas and Their Journey Beyond his Time. Profesor de filosofía política en varias universidades, es actualmente profesor invitado de la Universidad Francisco Marroquín, en Guatemala.
} 
Lo decía Platón en el Fedro, los libros, como la pintura son obras que parecen vivas pero están muertas. Estúpidamente, se repiten hasta el infinito ${ }^{2}$.

Por ejemplo: "Parmi les objets nouveaux qui, pendant mon séjour aux États-Unis, ont attiré mon attention, aucun n'a plus vivement frappé mes regards que l'égalité des conditions. Je découvris sans peine..."

Sin embargo, los textos son bastante menos estáticos de lo que se pueda pensar, especialmente en un autor como Alexis de Tocqueville.

Los lectores que acuden a las ediciones habituales de La democracia generalmente ignoran que el texto que leen no es exactamente idéntico al publicado en 1835 y 1840.

Después de haber redactado una primera versión de su obra en el llamado "manuscrito de trabajo", Tocqueville decidió presentar su libro ante el jurado de su familia y amigos. Gustave de Beaumont y Louis de Kergorlay habían jugado un papel importante en el trabajo de redacción, pero Tocqueville quería ofrecer entonces a su escrutinio la versión final antes de entregarla al editor.

Encargó, pues, una copia del manuscrito. Esa copia ha desaparecido y únicamente quedan algunos jirones de texto copiados en hojas que Tocqueville utilizó después para otros menesteres. De su lectura resulta evidente que el copista encontró grandes dificultades a la hora de descifrar la letra cuneiforme ${ }^{4}$ del escritor. Algunas notas entre los manuscritos indican que Tocqueville hubo de leerle al menos varios capítulos. Es evidente que el autor de la copia introdujo en ese momento en el texto algunos errores, que se han ido perpetuando.

Sea como fuere, en esa copia hoy perdida, Tocqueville escribió al lado de algunos fragmentos preguntas para los lectores y sus dudas sobre algunas partes que le parecían poco felizmente acabadas. Salvo esos comentarios, la copia da la impresión de haber sido muy parecida a la versión final del manuscrito de trabajo, que se conserva en la Universidad de Yale ${ }^{5}$. Sabemos esto porque los primeros críticos de la Democracia copiaron muchas veces, antes de sus críticas, los fragmentos a los que se referían. Así, es posible conocer las diferencias entre un texto y otro.

Pocas son las observaciones de Kergorlay que han sobrevivido, apenas unos retazos que corresponden a la introducción, pero parece ser el que más

\footnotetext{
${ }^{2}$ Platón, Fedro, 274c-276.

Ortega, haciendo eco a Platón, defendía que un libro es únicamente la ausencia de su autor. José Ortega y Gasset, "Comentario al Banquete de Platón", en Obras completas, Madrid, Alianza Editorial, 1983, IX, p. 766.

${ }^{3}$ Alexis de Tocqueville, Démocratie en Amérique, French and English bilingual edition edited by Eduardo Nolla, translated from the French by James T. Schleifer, Indianápolis, Liberty Fund, 2010, p. 3. El mismo texto está disponibles en una edición inglesa únicamente, Indianápolis, Liberty Fund, 2012, y en una traducción española de Eduardo Nolla en Madrid, Trotta, 2010 y 2018. Los números de página son los mismos en todas estas ediciones. De ahora en adelante citada como $D A$.

${ }^{4}$ Como él mismo la describe en una carta de 15 de febrero de 1856 a Theodore Sedgwick. En la Universidad de Yale, Yale Tocqueville Collection, Beinecke Library, DIIa.

${ }^{5}$ Yale Tocqueville Collection, Beinecke Library, New Haven. Connecticut, Universidad de Yale.
} 
estima reciba de Tocqueville. Casi idéntico crédito concede a Gustave de Beaumont. Tras las decisiones de los amigos, surgen las palabras de su hermano Édouard y, finalmente, las críticas de su padre Hervé, si bien es cierto que las de este último tienden a ser más estilísticas y gramaticales que las de los otros lectores.

Carecemos del texto final enviado al editor, pero sin duda, el proceso de impresión debió introducir también algún error.

Si se comparan las ediciones de 1835, 1838, 1840, 1848 y 1850, que son las principales y más reproducidas y traducidas y que fueron revisadas por el autor, se constata la corrección de algunos errores y la inclusión de otros nuevos.

Así, existen errores en el texto que son del propio Tocqueville y gazapos que introdujeron el copista y el proceso de edición, sin que sea posible determinar una diferencia, así como errores que se introducen en ediciones posteriores.

Muchas de estas discrepancias entre las distintas ediciones son meramente estilísticas. Otras se deben a errores del propio Tocqueville, pero no faltan las ocasiones en las que las equivocaciones de la imprenta cambian el sentido de las ideas del autor.

Tocqueville afirma: "Les pays aristocratiques sont remplis de particuliers riches et influents qui savent se suffire à eux-mêmes, et qu'on n'opprime pas aisément ni en secret. ${ }^{\text {" }}$

Pero en muchas ediciones se lee justo lo contrario: "Les pays aristocratiques sont remplis de particuliers riches et influents qui ne savent se suffire à euxmêmes, et qu'on n'opprime pas aisément ni en secret."

Cuando habla de los hechos que pueden ser objeto de dramatización en el teatro, habla de la ausencia de "catástrofes públicas", no de "catástrofes políticas", como se afirma.

Y cuando explica las relaciones entre los americanos entre sí nunca ha dicho que no existiera entre ellos "intimidad", sino que no existía entre ellos "enemistad"".

De la misma manera, establece que existe un vínculo secreto entre igualdad y revolución y no lo contrario como aseveran algunas versiones ${ }^{9}$.

Cerca del final de su obra reflexiona que "tous ceux qui, dans les siècles où nous entrons, essaieront d'appuyer la liberté sur le privilège ${ }^{10 ",}$, no como establecen otros textos, "l'autorité sur le privilège".

Todos estos errores y otros muchos están documentados más adelante.

\footnotetext{
${ }^{6} D A$, p. 1267 . He hecho referencia a estos y otros cambios en $D A$, p. xxxv, notas 16 y 17 .

${ }^{7} D A$, p. 851.

${ }^{8} D A$, p. 996.

${ }^{9} D A$, p. 1134.

${ }^{10} D A$, p. 1263.
}

Araucaria. Revista Iberoamericana de Filosofia, Política, Humanidades y Relaciones Internacionales, año $21, \mathrm{n}^{\circ} 42$ Segundo semestre de 2019. Pp. 387-397. ISSN 1575-6823 e-ISSN 2340-2199 doi: 10.12795/araucaria.2019.i42.16 
También se da el caso de ediciones en las que faltan algunos párrafos, que parecen haber sido censurados por su carácter crítico.

En la conocida edición del Fondo de Cultura Económica falta, por ejemplo, el siguiente texto:

Mais, pendant longtemps encore, l'état peu avancé de la civilisation, la corruption des moeurs et la misère, empêcheront le Mexique de prendre un rang élevé parmi les nations ${ }^{11}$.

Tampoco aparece esta reflexión poco amable con América del Sur:

Il n'y a cependant pas sur la terre de nations plus misérables que celles de l'Amérique du Sud.

Ainsi, non seulement les causes physiques ne peuvent amener des résultats analogues chez les Américains du Sud et ceux du Nord, mais ells ne sauraient même produire chez les premiers quelque chose qui ne fût pas inférieur à ce qu'on voit en Europe, où elles agissent en sens contraire ${ }^{12}$.

Con el fin de resolver las dudas sobre los textos y de ayudar a resolver algunas de las incongruencias que los estudiosos han hallado en la obra, se presentan a continuación unas tablas con los errores de distinto tipo que como editor he hallado al cotejar las ediciones citadas con los manuscritos de Tocqueville.

Las páginas hacen referencia a mi propia edición, donde estos errores han sido subsanados. Los números de página y de línea son idénticos en la edición bilingüe de cuatro volúmenes y en la edición solo en inglés y en dos volúmenes. Ambas publicadas en Indianápolis por Liberty Fund. Esos números de página se encuentran también, entre corchetes, en la edición española publicada en Madrid por Trotta. En esta última edición no coinciden, sin embargo, los números de las líneas.

${ }^{11} D A$, p. 276. Cf. en la edición de Méjico, Fondo de Cultura Económica, 2005, p. 163. Esta editorial está preparando una nueva traducción del libro.

${ }_{12}$ DA, p. 496. Cf. en la edición de Méjico, Fondo de Cultura Económica, 2005, p. 303. 


\section{Democracia de 1835}

\begin{tabular}{|c|c|c|c|}
\hline $\begin{array}{l}\text { Página en edición } \\
\text { LF }\end{array}$ & $\begin{array}{l}\text { En } \\
\text { ediciones }\end{array}$ & Debe decir & Observaciones \\
\hline 8 , línea 2 , ver la nota & 1270 & 1370 & 1370 en el manuscrito. La fecha correcta es 1270 \\
\hline 9, línea 32 & $\begin{array}{l}\text { l'obscur } \\
\text { aventurier }\end{array}$ & d'obscurs aventuriers & En el manuscrito. \\
\hline 14, línea 13 & des ruines qu'elles & des ruines qu'ell e & En el manuscrito \\
\hline 29, nota 1 & & & $\begin{array}{l}\text { El texto es diferente en la primera edición: "M. } \\
\text { Gustave de Beaumont, mon compagnon de voyage } \\
\text { en Amérique, compte publier, dans les premiers } \\
\text { jours de 1835, un livre intitulé Marie, ou } \\
\text { l'esclavage aux Etats-Unis. Le but..." }\end{array}$ \\
\hline 33, línea 7 & & $\begin{array}{l}\text { Nota en } \ldots \text { presque } \\
\text { égale }\end{array}$ & $\begin{array}{l}\text { Las primeras ediciones incluían un mapa y la nota: } \\
\text { "Voyez la carte placée à la fin du volume". }\end{array}$ \\
\hline 34 , línea 24 & 228,343 & 228,843 & Correcto en el manuscrito. \\
\hline 34 , nota 1 & p. 499 & p. 469 & $\begin{array}{l}\text { Correcto en el manuscrito. Error corregido en la } \\
\text { cuarta edición únicamente }\end{array}$ \\
\hline 35, nota 7 & 877 lieues & 897 lieues & Correcto en el manuscrito. \\
\hline 37 , nota 13 & vol. III & vol. V & $\begin{array}{l}\text { Correcto en el manuscrito, en la edición de } 1835 \text { y } \\
\text { en la de } 1837 \text { publicada en Bruselas. }\end{array}$ \\
\hline 42 , nota 16 & Hecwelder & Heckwelder & Error de Tocqueville. \\
\hline 42 , nota 16 & & & $\begin{array}{l}\text { La nota es diferente en otras ediciones, } \\
\text { conteniendo más referencias. Por ejemplo, en la } \\
\text { edición de } 1837 \text { en Bruselas. }\end{array}$ \\
\hline 52 , nota 2 & 1807 & 1707 & $\begin{array}{l}\text { Tocqueville cita la fecha correcta en el manuscrito } \\
\text { y en otros lugares. }\end{array}$ \\
\hline 54, nota 6 & p. 14 & p. 13 & $\begin{array}{l}\text { Es la p. } 13 \text { Correcto en el manuscrito, en la edición } \\
\text { de } 1835 \text { y en la de } 1837 \text { en Bruselas. }\end{array}$ \\
\hline 56, línea 7 & XIII, 15 & $\mathrm{XV}, 13$ & $\begin{array}{l}\text { Correcto en el manuscrito y en la edición de } \\
\text { Bruselas de } 1837 \text {. }\end{array}$ \\
\hline 56, nota 7 & p. 22 & pp. 23-24 & El manuscrito dice p. 23. \\
\hline 57, nota 9 & p. 35 & p. $35-36$ & Error de Tocqueville. \\
\hline 58 & $\begin{array}{l}\text { Falta una nota a } \\
\text { pie de página }\end{array}$ & $\begin{array}{l}\text { New England's } \\
\text { Memorial, p. } 37[-38 \\
\text { (Ed.)] }\end{array}$ & $\begin{array}{l}\text { La nota aparece en las ediciones de } 1835 \text { y de } 1837 \\
\text { en Bruselas. }\end{array}$ \\
\hline 58, nota 10 & History, p. 42 & History, vol. I, p. 43 & Error de Tocqueville. \\
\hline 60 , nota 12 & p. $11-31$ & $13-31$ & Correcto en el manuscrito. \\
\hline 61 , nota 14 & p. 35 & p. 36 & $\begin{array}{l}\text { El manuscrito indica la p. } 35 \text {. La edición de } 1837 \\
\text { en Bruselas dice p. } 36 .\end{array}$ \\
\hline 63 , nota 20 & Bedfort & Bedforde & De difícil lectura en el manuscrito. \\
\hline 63 , nota 20 & Jemmings & Jennings & Error de Tocqueville. \\
\hline 63 , nota 21 & p. 104 & p. $104-106$ & Error de Tocqueville. \\
\hline 63 , nota 21 & p. 435 & p. $435-436$ & Error de Tocqueville. \\
\hline 63 , nota 22 & $i d ., 1650, \mathrm{p}$. & Code of $1650, \mathrm{p}$. & Correcto en el manuscrito y en la edición de 1835. \\
\hline 63 , nota 25 & septembre & décembre & Correcto en el manuscrito. \\
\hline 65 , nota 29 & p. 17 & p. 12 & Error de Tocqueville. \\
\hline 65 , nota 30 & $\begin{array}{l}\text { l'exécution. Code } \\
\text { of } 1650, \ldots\end{array}$ & $\begin{array}{l}\text { l'exécution. Pitkin's } \\
\text { History, p. } 47 .\end{array}$ & $\begin{array}{l}\text { Erróneo como texto de la nota } 31 \text {. Correcto en el } \\
\text { manuscrito. }\end{array}$ \\
\hline 65 , nota 31 & Pitkin's History, & $\begin{array}{l}\text { Constitution de } 1638 \text {, } \\
\text { p. } 12 \text {. }\end{array}$ & $\begin{array}{l}\text { Erróneo como texto de la nota } 32 \text {. Correcto en el } \\
\text { manuscrito. }\end{array}$ \\
\hline 65 , nota 32 & Constitution... & Code of 1650 , p. 70. & $\begin{array}{l}\text { Erróneo como final de la nota } 30 \text {. Correcto en el } \\
\text { manuscrito. }\end{array}$ \\
\hline 67 , nota 39 & p. 90 & p. 91 & Error de Tocqueville. \\
\hline
\end{tabular}




\begin{tabular}{|c|c|c|c|}
\hline 67, nota 40 & p. 83 & p. 38 & Correcto en el manuscrito. \\
\hline 68, nota 41 & vol. II, p. 13 & vol. I, p. 113 & Error de Tocqueville. \\
\hline 68, línea 20 & $\begin{array}{l}\text { Llamada de la } \\
\text { nota en vie, en la } \\
\text { p. } 69\end{array}$ & $\begin{array}{l}\text { Llamada de la nota en } \\
\text { liberté }\end{array}$ & En las ediciones de 1835 y de 1837 en Bruselas. \\
\hline 72, nota 42 & p. 166 & p. 167 & Error de Tocqueville. \\
\hline 79, línea 14 & en quelque tête & en quelques têtes & En el manuscrito y en la edición de 1835 . \\
\hline 104, nota 2 & 22 février & 23 février & Error de Tocqueville. \\
\hline 105 , nota 3 & p. 475 & p. 473 & Correcto en el manuscrito. \\
\hline 106 , nota 4 & 25 mars & 23 mars & Correcto en el manuscrito. Cf. nota 7 en p. 110 . \\
\hline 106 , nota 4 & vol. I, p. 150 & vol. I, p. 250 & Correcto en el manuscrito. \\
\hline 107 , nota 6 & 1827 & 1829 & Correcto en el manuscrito. \\
\hline 110 , nota 9 & 8 mars & 10 mars & Error de Tocqueville. \\
\hline 114 , nota 10 & vol. I & vol. II & Correcto en el manuscrito. \\
\hline 115 , nota 13 & 1791 & 1781 & Correcto en el manuscrito. \\
\hline 119, nota 16 & p. 539 & p. 549 & Error de Tocqueville. \\
\hline 120, líneas 6 y 7 & comté de la & comté et de la & En el manuscrito. \\
\hline 121 , líneas $15 \mathrm{v}$ y 16 & $\begin{array}{l}\text { électeurs, } \\
\text { lorsque.... } \\
\text { l'élection il ne }\end{array}$ & $\begin{array}{l}\text { électeurs. Lorsque... } \\
\text { l'élection, il ne }\end{array}$ & En el manuscrito y en la edición de 1835 . \\
\hline 124, líneas 8 y 9 & & & $\begin{array}{l}\text { El párrafo que empieza "Il faut bien..." falta en } \\
\text { alguna edición. }\end{array}$ \\
\hline 128, nota 35 & p. 309 & pp. 307-308 & Error de Tocqueville. \\
\hline 129, nota 36 & 1.000 à 2.700 & 1.000 à 2.500 & Correcto en el manuscrito. \\
\hline 130, nota 37 & février 1834 & février 1824 & Correcto en el manuscrito. \\
\hline 135 , nota 42 & part. I, ch. $\mathrm{x}$ & part. I, ch. xii & Correcto en el manuscrito. \\
\hline 135 , nota 42 & ministère & ministère public & En el manuscrito. \\
\hline 169, línea 10 & il existe & elle existe & En el manuscrito. \\
\hline 177, línea 33 & $\begin{array}{l}\text { mensonge et } \\
\text { d'ignorance }\end{array}$ & $\begin{array}{l}\text { mensonge ou } \\
\text { d'ignorance }\end{array}$ & En el manuscrito y en la edición de 1848. \\
\hline 183, nota 2 & p. $85-115$ & p. $84-115$ & p. 85-114. Correcto en el manuscrito. \\
\hline 194, nota 13 & 329,514 & $329-514$ & Correcto en el manuscrito. \\
\hline 198, nota 14 & 69 & 65 & Error de Tocqueville. \\
\hline 198, nota 14 & p. 194 & p. 124 & Error de Tocqueville. \\
\hline 201, nota 16 & p. 255 & vol. I, p. 253 & Error de Tocqueville. \\
\hline 201, nota 16 & p. $515-780$ & p. $515-580$ & Correcto en el manuscrito. \\
\hline 208, nota 18 & 21 janvier & 28 janvier & Error de Tocqueville. \\
\hline 214, líneas 28 a 31 & Falta un párrafo & & $\begin{array}{l}\text { Párrafo eliminado por Tocqueville a partir de las } \\
\text { ediciones de } 1837 \text { por la queja de John Quincy } \\
\text { Adams. Ver la nota } \mathrm{k} \text { de las páginas } 214 \text { y } 215 \text {. }\end{array}$ \\
\hline 220 , nota 20 & $\begin{array}{l}\text { National } \\
\text { Calendar }\end{array}$ & $\begin{array}{l}\text { National Calendar, } \\
1833\end{array}$ & Correcto el manuscrito. \\
\hline 229, nota 24 & & $\begin{array}{lrr}\text { La nota } & \text { es } & \text { más } \\
\text { extensa } & \text { en } & \text { el } \\
\text { manuscrito } & & \end{array}$ & En el manuscrito \\
\hline 229 , nota 24 & 581,668 & $581-668$ & Correcto en el manuscrito. \\
\hline 232, línea 4 & ses tribunaux & ces tribuanux & En el manuscrito. \\
\hline 306, línea 11 & naissance & puissance & En el manuscrito y en las ediciones de 1835 y 1848 . \\
\hline 322, línea 6 & lutte égale & lutte légale & En el manuscrito y en las ediciones de 1835 y 1848 . \\
\hline 325, líneas 19 y 20 & Aucun... salaire. & & $\begin{array}{l}\text { Este párrafo está redactado de manera algo } \\
\text { diferente en el manuscrito. No aparece en la } \\
\text { edición de } 1835 \text {, pero sí en la de } 1848 \text {. }\end{array}$ \\
\hline 350 , ver nota $\mathrm{k}$ & $\begin{array}{l}\text { La richesse... } \\
\text { analyse }\end{array}$ & & Este párrafo es distinto en la edición de 1835. \\
\hline 371 , nota 17 & page 355 & page 353 & Correcto en el manuscrito. \\
\hline 371, nota 17 & guerre. En effet & guerre." En effet & La cita debe terminar en guerre". \\
\hline 435, línea 16 & la vie de l'ordre & la vue de l'ordre & En el manuscrito y en la edición de 1835. \\
\hline
\end{tabular}




\begin{tabular}{|c|c|c|c|}
\hline 437, línea 14 & prendre & rendre & $\begin{array}{l}\text { Correcto en el manuscrito y las ediciones de } 1835 \\
\text { y } 1848 .\end{array}$ \\
\hline 438, línea 31 & que la loi & que de la loi & En el manuscrito. \\
\hline 444 , nota 3 & which is counted & which is conceded & Correcto en el manuscrito. \\
\hline 460, línea 9 & l'étendue & l'inmense étendue & En el manuscrito. \\
\hline 492 , nota 7 & p. 244 & p. 249 & Error de Tocqueville. \\
\hline 499, línea 10 & les lois moins que & $\begin{array}{l}\text { les lois infiniment } \\
\text { moins }\end{array}$ & En el manuscrito y en la edición de 1848. \\
\hline 520 , nota 1 & 1810 & 1812 & Error de Tocqueville. \\
\hline 523 , nota 2 & 6.373 & 6.273 & Correcto en el manuscrito \\
\hline 523 , nota 2 & p. 20 & p. 90 & Correcto en el manuscrito \\
\hline 528 , nota 8 & 20.000 .000 & 29.000 .000 & Correcto en el manuscrito y la edición de 1835. \\
\hline 534 , nota 17 & Sénonville & Dénonville & Correcto en el manuscrito. \\
\hline 558 , nota 37 & 937.669 & 937.679 & Correcto en el manuscrito y la edición de 1835 . \\
\hline 577 , nota 51 & 2.010 .327 & 2.010 .527 & Correcto en el manuscrito. \\
\hline 577 , nota 51 & 319.439 & 319.467 & Correcto en el manuscrito. \\
\hline 577 , nota 51 & 2.329 .766 & 2.329 .994 & Correcto en el manuscrito. \\
\hline 578, línea 20 & l'État & l'état & En el manuscrito \\
\hline 591 , nota 53 & 17 mars & 14 mars & Error de Tocqueville. \\
\hline 593, línea 7 & entièrement & intimement & En el manuscrito. \\
\hline 603 , nota 61 & 12.856 .163 & 12.856 .165 & Correcto en el manuscrito y la edición de 1848 . \\
\hline 604 , nota 64 & 500 milles & 46.500 milles & Correcto en el manuscrito. \\
\hline 606 , nota 68 & 3.672 .371 & 3.672 .317 & $\begin{array}{l}\text { Correcto en el manuscrito y las ediciones de } 1835 \\
\text { y } 1848 .\end{array}$ \\
\hline 606 , nota 69 & p. 48 & p. 44 & El manuscrito indica la p. 43. \\
\hline 608 , nota 73 & $\begin{array}{l}\text { National } \\
\text { Calendar }\end{array}$ & $\begin{array}{l}\text { American Almanac, } \\
1832, \text { p. } 162\end{array}$ & Error de Tocqueville. \\
\hline 610 , nota 77 & aux congrès & au congrès & En el manuscrito y la edición de 1848. \\
\hline 638 , nota 91 & 10.731 .039 & 10.731 .037 & $\begin{array}{l}\text { Correcto en el manuscrito y en las ediciones de } \\
1835 \text { y } 1848 \text {. }\end{array}$ \\
\hline 638 , nota 91 & 101.129.266 & 101.029 .266 & Correcto en el manuscrito. \\
\hline 639 , nota 93 & 544.571 & 544.591 & Correcto en el manuscrito. \\
\hline 661 , nota c, línea 4 & Hecwelder & Heckwelder & El manuscrito dice Heckwelder \\
\hline 661 , nota c, línea 8 & Geiberger & Zeisberger & Error de Tocqueville. \\
\hline 664 , nota e, línea 15 & p. 525 & p. 535 & Correcto en el manuscrito. \\
\hline 672 , nota $\mathrm{f}$, línea 32 & 1630 & 1636 & Error de Tocqueville. \\
\hline 684 , nota $b$, línea 24 & $\begin{array}{l}\text { Voyez Delolme; } \\
\text { voyez }\end{array}$ & $\begin{array}{l}\text { Voyez Delolme, liv. I, } \\
\text { ch. IV; voyez }\end{array}$ & Correcto en el manuscrito y la edición de 1848. \\
\hline 684 , nota $b$, línea 25 & chap. XII & chap. XIII & Error de Tocqueville. \\
\hline 686 , nota c, línea 21 & p. 454 et 456 & p. 454 et 446 & $\begin{array}{l}\text { Correcto en el manuscrito y las ediciones de } 1835 \\
\text { y } 1848 .\end{array}$ \\
\hline
\end{tabular}




\section{Democracia de 1840}

\begin{tabular}{|c|c|c|c|}
\hline 709, línea 4 & suppose & suggère & En el manuscrito. \\
\hline 724, línea 12 & clairement & très clairement & En el manuscrito y la edición de 1848. \\
\hline 724, línea 19 & du grand nombre & du plus grand nombre & En el manuscrito y la edición de 1848. \\
\hline 731, línea 2 & je porte & je reporte & En el manuscrito y la edición de 1848. \\
\hline 732, línea 4 & ou de la & et de la & En el manuscrito y la edición de 1848. \\
\hline 734, línea 18 & de leurs fils & que leurs & En el manuscrito y la edición de 1848. \\
\hline 734, línea 19 & de leurs voisins & que leurs voisins & En el manuscrito y la edición de 1848. \\
\hline 736 , línea 13 & dans les détails & dans le détail & En el manuscrito y la edición de 1848. \\
\hline 738 , línea 22 & naturellement & mutuellement & En el manuscrito. \\
\hline 755 , línea 14 & défavorable & favorable & En el manuscrito y la edición de 1848. \\
\hline 767, línea 21 & & $\begin{array}{l}\text { particulières, aux arts que } \\
\text { les moyens de rendre la } \\
\text { vie aisée }\end{array}$ & Correcto en el manuscrito. \\
\hline 770, línea 1 & $\begin{array}{l}\text { ni caste, }, . . \mathrm{ni} \\
\text { classes }\end{array}$ & ni castes....ni classes & $\begin{array}{l}\text { En la edición de } 1848 \text {. El manuscrito dice } \\
\text { castes y classe. }\end{array}$ \\
\hline 771, línea 5 & des lumières & les lumières & En el manuscrito y en la edición de 1848. \\
\hline 771 , línea 25 & il y ait & qu'il n'y ait & En el manuscrito y la edición de 1848. \\
\hline 773 , línea 15 & simple artisan & humble artisan & En el manuscrito y la edición de 1848. \\
\hline 805 , línea 29 & la littérature & la vie littéraire & en el manuscrito y la edición de 1848. \\
\hline 808 , línea 10 & fortune & fortunes & En el manuscrito y la edición de 1848. \\
\hline 817 , línea 27 & ce but & ce résultat & en el manuscrito y la edición de 1848. \\
\hline 822 , línea 2 & ou l'éloignememt & et l'éloignement & $\begin{array}{l}\text { En la edición de } 1848 \text {. La frase está } \\
\text { redactada de manera distinta en el } \\
\text { mansusrito. }\end{array}$ \\
\hline 822 , línea 3 & eût suffi & eût suffit & Error en varias ediciones. \\
\hline 822 , línea 33 & ou de l'hébreu & et de l'hebreu & En el manuscrito y la edición de 1848 . \\
\hline & certains termes & certains tours & En el manuscrito. \\
\hline 840 , línea 4 & contraste & contrastes & En el manuscrito y en la edición de 1848. \\
\hline 840 , línea 6 & piété & pitié & En el manuscrito y la edición de 1848. \\
\hline 851 , línea 16 & terreur & horreur & En el manuscrito y la edición de 1848. \\
\hline 851 , línea 26 & $\begin{array}{l}\text { catastrophes } \\
\text { politiques }\end{array}$ & catastrophes publiques & En el manuscrito. \\
\hline 877, línea 14 & $\begin{array}{l}\text { aussi } \\
\text { aveuglément }\end{array}$ & ainsi avéuglement & $\begin{array}{l}\text { En la edición de } 1848 \text {. Este capítulo no se } \\
\text { encuentra en el manuscrito. }\end{array}$ \\
\hline 884 , línea 20 & isolement, ils se & isolement et ils se & En el manuscrito y la edición de 1848. \\
\hline 900, línea 8 & plus les & et plus les & En el manuscrito y la edición de 1848. \\
\hline 907, línea 25 & chacun d'eux & chacun d'entre eux & En el manuscrito y en la edición de 1848. \\
\hline 912, línea 1 & $\begin{array}{l}\text { il n'y a sur la terre } \\
\text { qu'une nation }\end{array}$ & $\begin{array}{l}\text { il n'y a qu'une nation sur } \\
\text { la terre }\end{array}$ & En el manuscrito y la edición de 1848. \\
\hline 912, línea 20 & plus les & et plus les & En el manuscrito. \\
\hline 914, línea 13 & toute chose & toutes choses & En el manuscrito y la edición de 1848. \\
\hline 915 , línea 29 & toute recontre & toutes rencontres & En el manuscrito y la edición de 1848. \\
\hline 916, línea 33 & être confondue & $\begin{array}{l}\text { d'association en matière } \\
\text { politique ne saurait être } \\
\text { entièrement confondue }\end{array}$ & Tocqueville se cita erróneamente a sí mismo. \\
\hline 920, línea 24 & tous les jours & tous les jours parmi nous & En el manuscrito y la edición de 1848. \\
\hline 926, línea 4 & éprouver & prouver & $\begin{array}{l}\text { Correcto en el manuscrito y la edición de } \\
1848 \text {. }\end{array}$ \\
\hline 939, línea 7 & prédicateurs & prédicateurs ambulants & En el el manuscrito y la edición de 1848. \\
\hline 944, línea 28 & trouble & troubles & En el el manuscrito y en la edición de 1848. \\
\hline 955, línea 18 & trouve & retrouve & En el el manuscrito y la edición de 1848 . \\
\hline 956, línea 24 & commode & plus commode & En el el manuscrito y la edición de 1848. \\
\hline 959, línea 3 & mêmes & meme & En el el manuscrito y en la edición de 1848. \\
\hline 967, línea 5 & ce pays & ces pays & En el el manuscrito y en la edición de 1848. \\
\hline 968, línea 15 & près & prêts & En el el manuscrito y la edición de 1848. \\
\hline
\end{tabular}




\begin{tabular}{|c|c|c|c|}
\hline 973, línea 5 & avec & et avec peine & $\begin{array}{l}\text { En la edición de } 1848 \text {. Este capítulo no se } \\
\text { encuentra en el mansucrito. }\end{array}$ \\
\hline 996, línea 4 & intimité & inimité & En el el manuscrito y la edición de 1848. \\
\hline 996, línea 13 & s'absorbent & s'abordent & En el el manuscrito y la edición de 1848. \\
\hline 998, línea 5 & cela même & cela seul & En el el manuscrito y la edición de 1848. \\
\hline 1001, línea 21 & indiqué & indiquée & $\begin{array}{l}\text { Correcto en el manuscrito y en la edición de } \\
1848 \text {. }\end{array}$ \\
\hline 1003, línea 13 & dus & dûs & $\begin{array}{l}\text { Correcto en el manuscrito y en la edición de } \\
1848 \text {. }\end{array}$ \\
\hline 1010, línea 21 & à un & en un & En el el manuscrito y la edición de 1848. \\
\hline 1014, línea 5 & se faire bien & pour le bien & En el el manuscrito y en la edición de 1848. \\
\hline 1017, línea 5 & recherchent & cherchent & En el el manuscrito y la edición de 1848. \\
\hline 1022, línea 25 & éclate & n'éclate & $\begin{array}{l}\text { Correcto en el manuscrito y en la edición de } \\
1848 \text {. }\end{array}$ \\
\hline 1023, línea 22 & long terme & longs termes & En el el manuscrito y en la edición de 1848. \\
\hline 1032, línea 6 & son fils & ses fils & En el el manuscrito y en la edición de 1848. \\
\hline 1044, línea 5 & d'abord & dès l'abord & En el el manuscrito y en la edición de 1848. \\
\hline 1048, línea 7 & américains & américaines & Correcto en el manuscrito. \\
\hline 1077, línea 6 & tissé & tissu & $\begin{array}{l}\text { Correcto en el manuscrito y en la edición de } \\
1848 \text {. }\end{array}$ \\
\hline 1077, línea 20 & $\begin{array}{l}\text { n'en trouve plus } \\
\text { trace }\end{array}$ & $\begin{array}{l}\text { qu'on n'en retrouve plus } \\
\text { la trace }\end{array}$ & $\begin{array}{l}\text { Correcto en el manuscrito y en la edición de } \\
1848 \text {. }\end{array}$ \\
\hline 1082, línea 8 & en démocratie & en démocraties & En el el manuscrito y en la edición de 1848. \\
\hline 1094, línea 20 & tout temps & tous temps & $\begin{array}{l}\text { Correcto en el manuscrito y en la edición de } \\
1848 \text {. }\end{array}$ \\
\hline 1119, línea 10 & de main en main & de mains en mains & En el el manuscrito y en la edición de 1848. \\
\hline $\begin{array}{l}\text { 1134, línea } 12 \\
1143 \text {, línea } 5\end{array}$ & $\begin{array}{l}\text { naissent } \\
\text { pensée }\end{array}$ & $\begin{array}{l}\text { ne naissent } \\
\text { pensées }\end{array}$ & $\begin{array}{l}\text { Correcto en el manuscrito y en la edición de } \\
\text { En el el manuscrito y en la edición de } 1848 \text {. }\end{array}$ \\
\hline 1144, línea 3 & à découvrir & à en découvrir & En el el manuscrito y en la edición de 1848. \\
\hline 1150, línea 22 & Oserai-je & Oserais-je & $\begin{array}{l}\text { Correcto en el manuscrito y en la edición de } \\
1848 .\end{array}$ \\
\hline 1154, línea 24 & seul le & seule le & $\begin{array}{l}\text { Correcto en el manuscrito y en la edición de } \\
1848 .\end{array}$ \\
\hline 1156, línea 2 & de langage & du langage & $\begin{array}{l}\text { Correcto en el manuscrito y en la edición de } \\
1848 \text {. }\end{array}$ \\
\hline 1156, línea 12 & avancer est & avancer y est & $\begin{array}{l}\text { Correcto en el manuscrito y en la edición de } \\
1848 \text {. }\end{array}$ \\
\hline 1158 , linea 15 & d'où l'on & d'où on a & $\begin{array}{l}\text { Correcto en el manuscrito y en la edición de } \\
1848 \text {. }\end{array}$ \\
\hline 1160, línea 16 & redouter & en redouter & En el el manuscrito y en la edición de 1848. \\
\hline 1163, línea 2 & elle reviente & elle devient & $\begin{array}{l}\text { En la edición de } 1848 \text {. Otra expresión en el } \\
\text { manuscrito. }\end{array}$ \\
\hline 1167 , nota 1 , línea 2 & l'officier vaut & l'officier est & En el el manuscrito y en la edición de 1848. \\
\hline 168, línea 26 & ; il n'est & ; et il n'est & $\begin{array}{l}\text { En la edición de 1848. Esta frase no aparece } \\
\text { en el manuscrito. }\end{array}$ \\
\hline 1177, línea 22 & \begin{tabular}{|lcc} 
et $\quad$ par des \\
exemples
\end{tabular} & et des exemples & En el el manuscrito y en la edición de 1848. \\
\hline 1179, línea 11 & est difficile & est très diffciile & En el el manuscrito y en la edición de 1848. \\
\hline 1179 , nota 2 , línea 1 & que les peuples & que ces peuples & $\begin{array}{l}\text { En la edición de } 1848 . \text { El manuscrito dice } \\
\text { les peuples. }\end{array}$ \\
\hline 1181, línea 16 & la population & leur population & En el el manuscrito y en la edición de 1848. \\
\hline 1183, línea 9 & réduite & détruite & $\begin{array}{l}\text { Correcto en el manuscrito y en la edición de } \\
1848 .\end{array}$ \\
\hline 1193, línea 6 & $\begin{array}{c}\text { importe } \\
\text { particulièrement }\end{array}$ & $\begin{array}{l}\text { importe donc } \\
\text { particulièrement }\end{array}$ & En el manuscrito y en la edición de 1848. \\
\hline
\end{tabular}




\begin{tabular}{|c|c|c|c|}
\hline 1196, línea 14 & de lumière & de lumières & En el el manuscrito y en la edición de 1848. \\
\hline 1202, nota 1, línea 8 & d'innovation & d'innovations & En el el manuscrito y en la edición de 1848. \\
\hline 1204, línea 14 & ces instincts & ses instincts & En el el manuscrito y la edición de 1848 . \\
\hline 1204, línea 18 & épargne & évite & En el el manuscrito y en la edición de 1848. \\
\hline 1217, línea 11 & les avantages & les seuls avantages & $\begin{array}{l}\text { En la edición de } 1848 \text {. Esta frase no existe en } \\
\text { el manuscrito. }\end{array}$ \\
\hline 1224, nota 2 , línea 7 & ses & ces agents & En el el manuscrito. \\
\hline 1230, línea 11 & d'Europe & de l'Europe & En el el manuscrito y en la edición de 1848. \\
\hline 1231, línea 1 & tribunaux & tribunaux spéciaux & En el el manuscrito y en la edición de 1848. \\
\hline 1235 , nota 5 , línea 2 & tient les & tient tous les & $\begin{array}{l}\text { En la edición de } 1848 \text {. En el manuscrito la } \\
\text { frase es diferente. }\end{array}$ \\
\hline 1243, línea 18 & que après & qu'après & En el manuscrito y en la edición de 1848. \\
\hline 1243, línea 21 & faut prendre & faut bien prendre & En el el manuscrito y en la edición de 1848. \\
\hline 1243, línea 26 & dans les & dans des & En el el manuscrito y en la edición de 1848. \\
\hline 1244, línea 30 & vaciller les & vaciller tous les & En el el manuscrito y en la edición de 1848. \\
\hline 1248, línea 4 & dans les & dans des & En el el manuscrito y en la edición de 1848. \\
\hline 1248 , línea 20 & et cruels & et même cruels & En el el manuscrito y en la edición de 1848. \\
\hline 1251, línea 7 & peu chaque & peu à chaque & En el el manuscrito y en la edición de 1848. \\
\hline 1259 , línea 7 & éteint peu & éteint ainsi peu & En el el manuscrito y en la edición de 1848. \\
\hline 1263, línea 4 & l'autorité & la liberté & En el el manuscrito y en la edición de 1848. \\
\hline 1263, línea 4 & essayeront & essaieront & En el el manuscrito y en la edición de 1848. \\
\hline 1264, línea 4 & digne de & digne d'eux & $\begin{array}{l}\text { Correcto en el manuscrito y en la edición de } \\
1848 \text {. }\end{array}$ \\
\hline 1267, línea 17 & qui ne savent & qui savent se & En el el manuscrito y en la edición de 1848. \\
\hline 1275, línea 18 & force, de & force et d'originalité & En el el manuscrito y en la edición de 1848. \\
\hline 1277, línea 13 & sortent de l'état & sortent du fond de & En la edición de 1848. \\
\hline 1283, línea 17 & mais d'assurer & mais de s'assurer & En el el manuscrito y en la edición de 1848. \\
\hline
\end{tabular}




\section{Referencias bibliográficas:}

José Ortega y Gasset, “Comentario al Baquete de Platón”, en Obras completas, Madrid, Alianza Editorial, 1983, IX.

Platón, Fedro.

Alexis de Tocqueville, La democracia en América, Méjico, Fondo de Cultura Económica, 2005.

Alexis de Tocqueville, Democracy in America, French and English bilingual edition edited by Eduardo Nolla, translated by James T. Schleifer, Indianápolis, Liberty Fund, 2010. 4 v.

Alexis de Tocqueville, Democracy in America, edited by Eduardo Nolla, translated by James T. Schleifer, Indianápolis, Liberty Fund, 2012. 2v

Alexis de Tocqueville, La democracia en América, edición crítica y traducción de Eduardo Nolla, Madrid, Trotta, 2010 y 2018. 
